\title{
LEGISLAÇÃO E AÇÕES VISANDO À DIVERSIDADE ÉTNICO-RACIAL NO ENSINO SUPERIOR: ESTUDO COMPARATIVO DOS PDIS DE IES PÚBLICAS E COMUNITÁRIAS GAÚCHAS
}

\author{
LEGISLATION AND ACTIONS AIMED AT ETHNIC-RACIAL DIVERSITY IN HIGHER \\ EDUCATION: COMPARATIVE STUDIES OF THE IDPS FROM PUBLIC AND \\ COMMUNITY HEIS IN RIO GRANDE DO SUL
}

\section{Rodrigo Lemos Simões}

Universidade Luterana do Brasil - ULBRA, Programa de Pós-Graduação em Educação, Brasil, rodrigo.lemossimoes@rede.edu.br

\author{
ARTICLE INF O \\ Article history: \\ Received 2020-04-11 \\ Accepted 2020-06-20 \\ Available online 2020-06-20
}

Palavras-chave: Ensino superior. Educação. Diversidade étnico racial. Políticas públicas. Plano de Desenvolvimento Institucional (PDI)

Keywords: Higher education. Education. Ethnic-racial diversity. Public policies. Institutional Development Plan (IDP)

Resumo: O presente artigo é o resultado de um estudo feito no curso de MBA - Gestão no Ensino Superior, promovido pelo Consórcio das Universidades Comunitárias Gaúchas (COMUNG) em parceria com a Universidade de Caxias do Sul (UCS). Tem como escopo a temática da legislação brasileira e das ações desenvolvidas por Instituições de Ensino Superior (IES) públicas e comunitárias gaúchas, visando à diversidade étnico-racial. A pesquisa foi desenvolvida através de uma análise comparativa do Plano de Desenvolvimento Institucional (PDI) de seis IES deste Estado, sendo três delas públicas e três comunitárias. Para tanto nos valemos da metodologia atinente à análise textual discursiva a fim de verificarmos a forma como as IES trabalham na perspectiva das ações voltadas às questões étnico-raciais, e se estas levam em consideração o que é preconizado na legislação brasileira a este respeito.

\begin{abstract}
This article is the result of a study made in the course of MBA - Higher Education Management, promoted by the Consortium of Community Universities of Rio Grande do Sul (COMUNG) in partnership with the University of Caxias do Sul (UCS). Its scope is the theme of Brazilian legislation and actions developed by public and community Higher Education Institutions (HEl) from Rio Grande do Sul, addressing ethnic-racial diversity. The research was developed through a comparative analysis of the Institutional Development Plan (IDP) of six $\mathrm{HEls}$ of the state, three of them public and three community. For that, it is used the methodology related to the discursive textual analysis in order to verify the way the HEIs work from the perspective of actions focused on ethnic-racial issues, and if they take into account what is recommended in the Brazilian legislation in this regard.
\end{abstract}




\section{Introdução}

O presente estudo aborda a forma como Instituições de Ensino Superior (IES) públicas e comunitárias do Rio Grande do Sul desenvolvem suas ações em relação às questões étnicoraciais tendo por base seus documentos legais. Para isto, foram analisados o Plano de Desenvolvimento Institucional (PDI) de seis IES gaúchas, três públicas e três comunitárias, doravante denominadas IES P1, IES P2 e IES P3 para as IES públicas e IES C1, IES C2 e IES C3 para as IES comunitárias. Foi por nós escolhido o PDI como documento a ser analisado uma vez que este é por excelência o local onde são reunidas as informações a respeito da IES no que se referem a sua missão, metas e objetivos. Conforme consta no Formulário do Plano de Desenvolvimento Institucional - PDI/MEC, o documento deve ser construído no sentido de abranger um período de cinco anos, devendo as informações sobre a IES estarem organizadas em três níveis hierárquicos: Dimensões, Categorias de Análise e Indicadores. (BRASIL, MEC/SAPIENS, 2015). Optamos em trabalhar sobre a temática das relações étnico-raciais no ensino superior por acreditarmos que existe um déficit entre o que é preconizado pelo Governo Federal em suas leis, resoluções e pareceres, e o que vem sendo feito pelas IES no sentido de atender a demanda legal. Neste sentido, adotamos como base de referência o Parecer CNE/CP 3/2004, que trata das Diretrizes Curriculares Nacionais para a Educação das Relações Étnico-Raciais e para o Ensino de História e Cultura Afro-Brasileira e Africana e a Resolução CNE/CP n $1 / 2004$, que Institui Diretrizes Curriculares Nacionais para a Educação das Relações Étnico Raciais e para o Ensino de História e Cultura AfroBrasileira e Africana, além de outras leis, decretos ou resoluções devidamente referenciados ao longo do texto.

Decidimos abordar o tema a partir de um estudo comparativo entre seis IES gaúchas, primeiro por acreditarmos que este tipo de abordagem quando empregado nas questões voltadas à educação permite uma melhor compreensão dos avanços em um dado cenário a partir das ações empreendidas por distintos atores num mesmo campo (DIMMOCK, 2010). Segundo, por identificarmos no caráter público e/ou comunitário das IES analisadas, características comuns dentro de um quadro estrutural distinto. Neste sentido, desenvolvemos um trabalho de categorização sobre o corpus documental a fim de procedermos na comparação entre as unidades definidas como relevantes ao estudo (MORAES; GALIAZZI, 2007). Priorizamos na análise a abordagem qualitativa por acreditarmos, assim como Flick (2004), que esta melhor nos auxiliaria na compreensão de contextos sociais a partir das perspectivas dos sujeitos investigados. 


\section{Educação Superior no RS: as IES comunitárias}

A Educação Superior no Rio Grande do Sul tem início na cidade de Porto Alegre, com a fundação da Escola de Farmácia e Química, no ano de 1895, da Escola de Engenharia, em 1896, da Faculdade de Medicina de Porto Alegre, em 1898, e da Faculdade de Direito, em 1900. No ano de 1934, foi criada a Universidade de Porto Alegre, embrião do que viria a se tornar a Universidade Federal do Rio Grande do Sul. As faculdades criadas e mantidas pelos Irmãos Maristas na década de 1930 e 1940 na cidade de Porto Alegre irão formar a Universidade Católica do Rio Grande do Sul, assim denominada a partir do ano de 1948, quando por decreto presidencial alcançou o status de universidade. Esta foi também a primeira universidade privada do Estado, tendo por característica seu caráter filantrópico e confessional. Segundo dados da Secretaria de Educação do Estado do Rio Grande do Sul, o Estado conta hoje, com sessenta e duas instituições de ensino superior devidamente cadastradas em seu sistema. Destas, apenas treze são instituições púbicas, sendo as demais, instituições privadas. Conforme o Conselho Nacional de Educação existem diferentes caracterizações de Instituições de Ensino Superior no país, sendo que, conforme o Artigo 20 da Lei 9.394/96, as IES privadas, mantidas e administradas por pessoas físicas ou jurídicas de direito privado, são classificadas em Particulares, Comunitárias, Confessionais e Filantrópicas.

Em relação às IES comunitárias, o mesmo documento afirma que elas autodenominam-se ñpúblicas não estataisò uma vez que mantêm ñum elevado grau de interação no contexto socialò das regiões onde se encontram presentes. O modelo de IES comunitária teve sua origem no sul do Brasil, em Santa Catarina e no Rio Grande do Sul, tendo como objetivo maior a interiorização da educação superior nestes Estados. A Associação Catarinense das Fundações Educacionais - ACAFE, criada no ano de 1974 e o Consórcio das Universidades Comunitárias Gaúchas ï COMUNG, criado no ano de 1993, são entidades sem fins lucrativos que representam o conjunto de IES privadas de caráter comunitário. Contudo, e conforme o documento/contribuição do COMUNG e da ACAFE para a elaboração do Documento Referência do Fórum Nacional de Educação Superior, estas instituições, ao contrário das demais IES privadas:

[...] surgiram da associação entre poderes públicos locais e os diversos segmentos da sociedade civil a partir da segunda metade do século XX, têm sido confundidas com empresas que concebem a educação como mercadoria e negócio lucrativo. Tal confusão conceitual tem dificultado que o conjunto de universidades comunitárias [...] seja reconhecido na contribuição histórica que realizaram em termos de:

1) Democratização do acesso e flexibilização de modelos de formação;

2) Busca pela qualidade e por mecanismos consistentes de autoavaliação;

3) Compromisso social e inovação. (ACAFE, 2008, p.1). 
Desde o ano de 1995, o Distrito Federal sedia a Associação Brasileira das Universidades Comunitárias - ABRUC, uma associação civil, sem fins lucrativos, que congrega, por seus dirigentes máximos, Instituições de Ensino Superior Comunitárias Brasileiras. (ABRUC, 1995). A ABRUC desempenhou um importante papel junto aos poderes públicos durante todo o período de tramitação do Projeto de Lei no. 7639/2010, até o decreto do Congresso Nacional e a sanção da Presidência da República da Lei 12881/2013, onde são reconhecidas oficialmente as universidades comunitárias.

Conforme Venanzi e Sandano (2014, p. 149):

O reconhecimento das universidades comunitárias é uma reivindicação antiga, que começou a ganhar visibilidade em 1995, com a fundação da Associação Brasileira das Universidades Comunitárias (ABRUC). A Lei 12.881 foi preparada, desde 2006, com várias proposições da ABRUC no MEC e no Congresso Nacional.

A partir da Lei 12881/2013, as IES Comunitárias passaram a ter o direito a receber recursos orçamentários do governo federal para o desenvolvimento de atividades de interesse público, assim como ter acesso aos editais de órgãos governamentais de fomento direcionados às instituições públicas. No art. $6^{\circ}$ da Lei, fica instituído o Termo de Parceria que passará a ser firmado entre o poder público e as IES Comunitárias, a fim de formalizar o vínculo de cooperação entre ambos. Neste sentido, o repasse de recursos orçamentários e a possibilidade de participação nos editais até então destinados às IES públicas, permitirá que continuem sendo desenvolvidos programas e ações destas instituições no campo social, especialmente no que tange a trabalhos de cunho social voltados à saúde pública, ao desenvolvimento local, à inclusão e à cidadania. A Lei também vai ao encontro de uma reivindicação antiga das IES comunitárias em relação à interiorização e aplicação de recursos públicos em locais já alcançados por estas. Neste sentido, fica estabelecido que a parceria junto aos órgãos públicos estatais tendo como objetivo, além da oferta dos serviços de interesse público, a otimização dos recursos físicos e humanos existentes nas IES Comunitárias, a fim de evitar a ampliação ou duplicação por vezes desnecessária de estruturas físicas e capital humano, assegurando assim que os recursos públicos sejam utilizados da melhor forma.

\section{Apontamentos relativos à regulação do Ensino Superior no Brasil: o PDI e o PPI}

Uma vez iniciado o processo de credenciamento, a IES e sua mantenedora deverão fornecer a documentação necessária para que posteriormente seja feita a avaliação in loco pelo INEP. Entre os documentos exigidos para que se consiga proceder na homologação do parecer do Conselho Nacional de Educação - CNE é o Plano de Desenvolvimento Institucional (PDI). Conforme Segenreich (2005, p.152), o PDI como proposta governamental tem suas raízes em duas atribuições definidas pela LDB que são de competência do MEC: 
credenciamento e avaliação institucional. Neste sentido, o Decreto nำ5.773/2006, em seu artigo 16, determina que este documento deva conter a missão, objetivos e metas da instituição, o seu Projeto Pedagógico (PPI), o cronograma de implantação e desenvolvimento seu e dos seus cursos, a organização didático-pedagógica, o perfil do corpo docente, a organização administrativa, sua infraestrutura física, a oferta de educação à distância e dos seus cursos de pós-graduação stricto sensu, assim como o demonstrativo de sua capacidade e sustentabilidade financeiras. O PDI é acima de tudo, um instrumento de gestão, um documento onde são explicitados além do histórico institucional, sua missão e diretrizes pedagógicas, informações relativas aos seus objetivos, metas e estratégias de desenvolvimento, ou seja, tal qual um modelo de planejamento estratégico, onde são estipulados os objetivos e metas, no PDI são demonstradas as ações que a IES pretende desenvolver em um período de cinco anos, com vistas ao desenvolvimento e fortalecimento institucional.

Conforme consta no item III art. $3^{\circ}$ da lei dos SINAES, é importante que seja enfatizada a responsabilidade social das IES, posto que seus desdobramentos compõem um quadro onde emergem temáticas relevantes do debate atual a respeito do papel a ser desempenhado pela universidade, além daqueles que historicamente já vêm ocupando. A inclusão social, o desenvolvimento econômico e social, a defesa do meio ambiente, da memória cultural, da produção artística e do patrimônio cultural são questões que estão na ordem do dia em todos os países, não sendo diferente no que diz respeito ao Brasil. Neste sentido, e conforme consta no artigo 16 do Decreto no 5.773/2006, é no Projeto Pedagógico Institucional (PPI), que são explicitados os aspectos relacionados aos princípios filosóficos e à organização didáticopedagógica, devendo constar as políticas de gestão, ensino, pesquisa e extensão, assim como os aspectos relativos à forma como se dá a responsabilidade social da IES. O PPI tem relação direta com a missão, a visão e os objetivos da IES. Busca equalizar as demandas emergentes da sociedade contemporânea, como é o caso da responsabilidade social, demonstrando que a formação profissional se dá mediante a socialização e a produção de novos conhecimentos, e que estes devem acontecer em sintonia com questões prementes ao mundo contemporâneo, tais como a inclusão, a acessibilidade, a equidade, a sustentabilidade e outros tantos.

Neste sentido, ao que se refere aos dois documentos, podemos concluir que:

O PDI e o PPI trazem a realidade ampla das configurações da IES como fontes de relações norteadoras gerais [...] O PDI traz a caracterização geral da IES em caráter descritivo, denso, nomeando parte a parte toda a constituição administrativa, pedagógica e de pessoas que determinam o perfil da IES. Do PDI emanam as diretrizes norteadoras do agir institucional, conjuntamente ao Regimento que o apoia nas orientações nucleares. O PPI vem trazendo o conjunto referencial da IES com relação às suas opções pedagógicas, descrevendo suas concepções na área 
da educação, buscando orientar o desenvolvimento acadêmico geral da IES. O PPI é o documento institucional que reúne todos os cursos oferecidos na IES, caracterizando-os, sucintamente, de modo a organizar a rede das macro perspectivas das áreas do conhecimento; também constitui bases teóricas e legais ao desenvolvimento e organização dos PPCs. (PICAWY, 2008, p.96).

Não se trata, portanto, de documentos meramente burocráticos, mas de instrumentos políticos e filosóficos com bases teórico-metodológicas que levam em consideração a trajetória histórica da IES, sua missão e inserção no cenário local e regional assim como sua visão de futuro.

\section{Inclusão social e políticas públicas: as questões étnico-raciais na educação}

Segundo Mir (2004), por mais de trezentos anos a dominação colonial no Brasil produziu ressentimentos sociais e étnicos reafirmados pelos teóricos da independência e dirigentes do novo Estado. Tal fato torna-se evidente quando se consultam informações do Instituto Brasileiro de Geografia e Estatística - IBGE, do Ministério da Justiça/Sistema Integrado de Informações Penitenciárias - InfoPen ou da Organização das Nações Unidas para a Educação, a Ciência e a Cultura - UNESCO, no que diz respeito à relação escolaridade, raça, renda e perfil da população carcerária brasileira. Ainda que a Lei 1.390 de autoria do deputado federal Afonso Arinos de Melo Franco, proibindo a discriminação racial no Brasil date do ano de 1951, e a Constituição Brasileira de 1988 em seu artigo 3o, inciso I, estabeleça a promoção do bem estar de todos, sem preconceito de origem, raça e quaisquer outras formas de discriminação, fez-se necessária a criação de leis que garantissem o acesso da população afrodescendente ao ensino superior. Tratam-se das ações afirmativas transformadas em leis e que visam combater desigualdades atuando como instrumentos de equidade em favor dos grupos desfavorecidos na sociedade.

Conforme Santos:

Ação Afirmativa é tratar de forma preferencial aqueles que historicamente foram marginalizados, para que Ihes sejam concedidas condições equidistantes aos privilegiados da exclusão. Diferencia-se drasticamente da redistribuição, já que não é simples busca de diminuição de carência econômica, mas sim uma medida de justiça, tendo por base injustas considerações históricas que erroneamente reconheceram e menosprezaram a identidade desses grupos discriminados. (2005, p. 46).

O movimento da sociedade civil em favor de medidas reparatórias junto à população afro-descente brasileira remonta a primeira metade do século $X X$, sem que com isso tenham sido alcançadas mudanças significativas. A retomada do crescimento do movimento negro a partir da década de 1970 assim como o trabalho desenvolvido por políticos como é o caso dos deputados Abdias Nascimento na década de 1980 e dos deputados federais Florestan Fernandes e Paulo Paim assim, do senador Antero Paes de Barros e da 
senadora Benedita da Silva na década de 1990, abriram espaço para que no governo Fernando Henrique Cardoso fosse criado uma série de políticas públicas voltadas à promoção da igualdade racial, contribuindo significativamente para o avanço do debate sobre as relações raciais no Brasil na década seguinte. (PAULA, 2010, p.123-124). No ano de 2010 o Presidente Luiz Inácio Lula da Silva sancionou a Lei oㅜ 12.288, instituindo o Estatuto da Igualdade Racial a fim de assegurar que se efetivasse junto à população negra, a igualdade de oportunidades, garantindo assim a defesa dos direitos étnicos e o combate à discriminação no país. No ano de 2012 foi sancionada a Lei o 12.771 que dispõe sobre o ingresso de pessoas autodeclaradas pretas, pardas e indígenas nas universidades federais, bem como nas instituições federais de ensino técnico de nível médio. Antes disso, no ano de 2003, foi

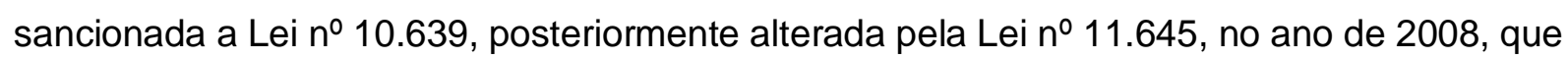
estabeleceu a obrigatoriedade da temática a respeito da História e Cultura Afro-Brasileira nos currículos dos estabelecimentos de ensino fundamental e ensino médio, públicos e privados de todo o Brasil. No ano de 2004, a Resolução CNE/CP № 1/2004, institui as Diretrizes Curriculares Nacionais para a Educação das Relações Étnico Raciais e para o Ensino de História e Cultura Afro-Brasileira e Africana. Em relação ao ensino superior, fica estabelecido que:

\begin{abstract}
art. $1^{\circ}$ A presente Resolução institui Diretrizes Curriculares Nacionais para a Educação das Relações Étnico-Raciais e para o Ensino de História e Cultura AfroBrasileira e Africana, a serem observadas pelas Instituições de ensino, que atuam nos níveis e modalidades da Educação Brasileira e, em especial, por Instituições que desenvolvem programas de formação inicial e continuada de professores. $\S 1^{\circ}$ As Instituições de Ensino Superior incluirão nos conteúdos de disciplinas e atividades curriculares dos cursos que ministram, a Educação das Relações ÉtnicoRaciais, bem como o tratamento de questões e temáticas que dizem respeito aos afrodescendentes, nos termos explicitados no Parecer CNE/CP 3/2004.

$\S 2^{\circ} \mathrm{O}$ cumprimento das referidas Diretrizes Curriculares, por parte das instituições de ensino, será considerado na avaliação das condições de funcionamento do estabelecimento. (BRASIL, RESOLUÇÃO CNE/CP № 1/2004).
\end{abstract}

Tendo por base o estabelecimento de políticas de ações afirmativas destinadas à reparação, reconhecimento e valorização da história, cultura e identidade afrodescendentes no Brasil, o Parecer CNE/CP 3/2004 referido na Resolução CNE/CP no 1/2004 trata da regulamentação do ensino de História e Cultura Afro-Brasileira e Africana nos diferentes níveis de ensino. Nele, temos estabelecidas as diretrizes que orientam a formulação de projetos e, no caso do ensino superior, a veiculação da rÉducação das Relações Étnico-Raciais, de conhecimentos de matriz africana e/ou que dizem respeito à população negraò devendo estes ser ministrados tanto nos conteúdos das disciplinas como também nas demais atividades curriculares dos cursos oferecidos pela IES, que passará a ser avaliada neste sentido. 


\section{Análise das relações étnico-raciais nas IES}

As três primeiras IES analisadas são instituições públicas, todas elas da rede federal de ensino superior. O PDI da IES P1 é um documento produzido coletivamente, sendo que a sua primeira versão foi apresentada à comunidade universitária, servindo de base para uma ampla discussão que envolveu docentes, discentes, quadro técnico-administrativo e membros da sociedade que desejassem contribuir com sua experiência para o fortalecimento da IES. Trata-se de um planejamento em nível estratégico onde as grandes linhas e objetivos institucionais, são dadas a conhecer, bem como os meios para alcançá-los. Segundo o texto, cada gestão deve apresentar um Plano Tático para a realização do PDI, contendo as decisões a serem tomadas em relação aos caminhos que serão percorridos a fim de se chegar aos objetivos propostos no documento. O caráter estratégico e democrático adotado se deve a escolha feita em deixar aos futuros gestores a escolha de como proceder em relação à trajetória da universidade, seu desenvolvimento e excelência acadêmica. (IES P1, PDI, 2011, p.4-5,). A Universidade explicita em sua Missão, o compromisso que assume em relação aos direitos humanos, especialmente [̃...] com o respeito às diferenças, étnicas, crenças e gênerosò (IES P1, PDI, 2011, p.7). Em seu Projeto Pedagógico Institucional faz referência à adoção de políticas específicas para a graduação, e também à criação e manutenção de programas destinados aos acadêmicos que tenham ingressado a partir de políticas de ações afirmativas, contudo, não especifica quais são os programas destinados a estes estudantes. O mesmo é reafirmado quando se trata da responsabilidade social da IES, seu empenho no trabalho desenvolvido em favor da inclusão social, dentre outras formas, a partir das políticas afirmativas (IES P1, PDI, p.25).

A segunda IES pública analisada tem sua criação vinculada ao processo de interiorização do ensino universitário público no Brasil. Seu PDI representa para a IES o início de um importante processo de desenvolvimento e crescimento institucional. Neste sentido, foi concebido em um processo participativo envolvendo gestores, servidores, estudantes e comunidade externa. Foram realizadas várias ações que possibilitaram o estreitamento do diálogo e a integração entre os diferentes segmentos envolvidos na construção do documento. Também foram feitas diversas reuniões de trabalho onde se buscou avançar na discussão a partir da troca de experiências, inclusive com outras IES, tendo sido analisados seus PDIs a fim de ampliar o conhecimento a respeito do instrumento. (IES P2, PDI, 2011, p.18-24). No Perfil Institucional da IES, um dos eixos norteadores trata da inclusão, acesso e acessibilidade, cooperação e inserção social, a fim de atender as necessidades da região. Em seu PPI, consta que a universidade aprovou no ano de 2007 um programa de ações afirmativas de inclusão racial e social. A IES P2 conta ainda com um Núcleo de Estudos AfroBrasileiros (NEAB), e uma Comissão de Implementação e Acompanhamento do Programa de Ações Afirmativas de Inclusão Racial e Social, composta por 22 representantes dos diversos setores da IES e da comunidade externa. 
Segundo consta no documento:

A comissão apresenta como objetivos principais: (i) apoiar o estudante garantindoIhe a permanência na Universidade com aproveitamento, até a colação de grau, viabilizando a transformação da legislação em efetivo mecanismo de redução das desigualdades sociais; (ii) democratizar o acesso aos cursos de graduação e a permanência neles dos candidatos oriundos dos segmentos da sociedade historicamente discriminados; e (iii) proporcionar condições de integração e igualdade no acesso à educação entre toda a comunidade discente (cotistas e não cotistas). (IES P2, PDI, 2011, p. 138).

A terceira das IES públicas analisada tem sua criação vinculada ao processo de expansão e renovação das Instituições Federais de Educação Superior ocorrido ao longo dos anos 2000 , tendo seu pleito iniciado a partir da proposição dos dirigentes dos municípios da região junto ao Ministério da Educação. No ano de 2007 iniciaram-se os trabalhos da Comissão de Implantação da nova IES, que foi oficialmente criada no ano de 2008 (IES P3, PDI, p. 14-16). O PDI da IES P3 é um documento elaborado pela comunidade acadêmica, tendo como objetivo o planejamento da consolidação e expansão da Universidade. Trata-se de uma construção coletiva, que passou por diferentes etapas onde as unidades universitárias e administrativas da IES puderam participar através do site do PDI, via moodle e através de encontros presenciais, debatendo os pontos levantados como importantes pela comunidade acadêmica, e pelas comissões de representação dos campi e da Reitoria, até que se chegasse a sua versão final. (IES P3, PDI, 2014, p.5-7). A IES P3 explicita no quesito Responsabilidade Social o compromisso institucional de ñ...] contribuir para a construção de uma sociedade que promova a igualdade de oportunidades e a inclusão socialò (IES P3, PDI, 2014, p. 36). A IES possui um Programa de Ações afirmativas voltado ao acompanhamento dos estudantes a fim de garantir-lhes não só no acesso ao ensino superior, mas também na sua permanência.

Conta ainda com uma Comissão Especial de Estudos sobre ñHistória e Cultura AfroBrasileira e Indígenaò além de uma política institucional que:

[...] entre outras perspectivas, visa à inclusão social, proporcionando o acesso e a continuidade dos estudos inclusive aos grupos que, historicamente, estiveram marginalizados e alijados do direito ao Ensino Superior público e gratuito. Além disso, deve promover a estruturação de percursos formativos flexíveis e diversificados, calcados no respeito às diferenças e na liberdade de pensamento $e$ expressão, sem discriminação de qualquer natureza. (IES P3, PDI, 2014, p. 29).

A primeira das três IES comunitárias que analisamos iniciou suas atividades na década de 1970, sendo que no início dos anos 1990 teve andamento o processo para a sua constituição enquanto universidade. Porém, com a alteração da legislação, passou-se ao credenciamento como Centro Universitário, o que ocorreu no final da referida década. O Plano de Desenvolvimento Institucional da IES C1 tem suas origens numa caminhada que remonta 
ao ano de 1998, quando a primeira matriz organizacional foi elaborada. Desde então, outras quatro versões chegaram à comunidade acadêmica, inclusive a que analisamos, e que é o resultado do trabalho coletivo, onde participaram representantes dos diversos segmentos da IES. Foi um longo processo de estudos, discussões e sistematizações até se chegasse ao documento final, onde são apresentadas as bases para o seu crescimento sustentável. (IES C1, PDI, 2018, p.7). Em seu PDI, quando trata dos objetivos e metas institucionais, bem como em relação à responsabilidade social assumida, destaca-se o compromisso da IES em relação à inclusão social. Em sua missão, princípios e visão, ao abordar a dimensão legal, são feitas referência à Educação das Relações Étnico-Raciais e ao Ensino de História e Cultura Afrobrasileira e Indígena, citando o Parecer CNE/CP 3/2004 e Resolução CP/CNE n 01, de 17 de junho de 2004.

Neste sentido, a IES promove:

Por meio da organização curricular dos diferentes cursos, busca propiciar uma sólida formação teórica e prática que responda às exigências contemporâneas da formação profissional. Para tanto, além das Diretrizes Curriculares Nacionais (DCN) para os cursos de graduação, a Instituição atende, também, ao que está prescrito na legislação referente à Política de Educação Ambiental, à Educação em Direitos Humanos e à Educação das Relações Étnico-Raciais e ao Ensino de História e Cultura Afro-Brasileiras e Indígenas. (IES C1, PDI, 2014, p. 18).

A dimensão da educação das relações étnico-raciais foi introduzida nos Projetos Pedagógicos dos Cursos da IES a fim de garantir uma organização curricular capaz de assegurar o cumprimento dos aspectos legais relativos ao ensino da história e cultura afrobrasileiras e africanas. Neste sentido, busca-se não apenas a informação, mas a produção de novos conhecimentos capazes de e promover o entendimento das diferentes identidades e culturas que compõem o quadro étnico nacional, assegurando o respeito à pluralidade e aos direitos legais.

A segunda das IES comunitárias analisada teve o seu PDI elaborado a partir da participação efetiva da comunidade acadêmica. Concebido como um conjunto de ferramentas de gestão e governança, o documento [̃....] possibilita a percepção da realidade, avaliação dos caminhos e construção de um referencial de futuro para uma organização que tem como objetivo alcançar sua visão e missão de sua existênciaò (IES C2, PDI, 2013, p.6-9). Nele, podem ser encontrados objetivos, indicadores e metas que irão dar os rumos do que será adotado em termos de política universitária, nos níveis estratégico, tático e operacional, a fim de consolidar o trabalho desenvolvido pela IES na região. Em seu PDI, ao tratar do perfil institucional, a IES destaca que um dos objetivos a ser alcançado está relacionado à forma como ela se insere no contexto local face à inclusão e ao desenvolvimento econômico e social. Faz parte de suas políticas de gestão o trabalho voltado à inclusão social daqueles que đ̃...] se encontram à margem de saberes, recursos, benefícios disponíveis à facilitação da vida, 
pela partilha de bens e serviços; ao acesso a novos patamares socioeconômicos, culturais, políticos e científico-tecnológicosò (IES C2, PDI, 2013, p. 26).

A terceira das IES comunitárias que analisamos iniciou suas atividades na década de 1930, e tem o seu PDI elaborado com base no Plano Estratégico da IES, sob o mesmo período de vigência. Conforme consta no documento, foi ñ...] a partir das análises dos ambientes externo e interno e de tendências e projeções [...]ò (IES C3, PDI, 2011, p.9) que foi desenvolvido este instrumento, a fim de servir aos processos futuros de tomada de decisão em relação à trajetória a ser por ela percorrida. Em seu PPI, no item que trata do perfil do egresso, fica evidenciado o objetivo de desenvolver ao longo da formação acadêmica de seus estudantes a educação voltada para a cidadania, tendo como um dos vetores a inclusão social. Neste sentido, espera que os egressos sejam pessoas abertas $\tilde{\eta}$....] às relações pessoais, à diversidade, ao diálogo e à convivênciaò (IES C3, PDI, 2011, p. 22).

\section{Considerações finais}

A Resolução № 1, de 17 de junho de 2004, estabelece que as instituições de ensino, inclusive as de educação superior, devam promover uma série de ações voltadas ao mapeamento, reconhecimento, registro e ensino da História e Cultura Afro-Brasileira e Africana, assim como da Educação das Relações Étnico-Raciais. Este documento tem como base o Parecer CNE/CP 3/2004, que apresenta uma série de proposições relativas à temática, detalhando como os diferentes agentes podem e devem orientar suas práticas.

Tais documentos são fundamentais no sentido de subsidiarem as IES na construção do Projeto Pedagógico Institucional ï PPI, e o Plano de Desenvolvimento Institucional ï PDI, especialmente no que se refere às questões étnico-raciais no ensino superior. Contudo, conforme tivemos a oportunidade de observar, eles são pouco utilizados e, presumimos que sejam também muitas vezes desconhecidos pela comunidade acadêmica.

O parecer supracitado é bastante claro nas suas referências em relação às práticas possíveis de serem desenvolvidas pelas instituições de ensino em relação à temática em foco, contudo, pouco se pôde apurar neste sentido quando da leitura dos PDls utilizados na pesquisa.

Os documentos das IES pesquisadas podem ser classificados em três níveis dentro do quesito refetivação das políticas relativas às questões étnico-raciaisò Alguns deles demonstram que estão objetivamente desenvolvendo ações que causam o impacto desejado no sentido de se efetivarem tais políticas em favor do reconhecimento da diversidade e da valorização da cultura e história da população afro-brasileira. Outros que se colocam na posição de uma r̃arta de intensõesò mas que efetivamente não demonstram onde e como as ações preconizadas se efetivam. E aquelas instituições que omitem tais questões. 
Um exemplo disso pode ser observado no fato de termos trabalhado a partir de algumas categorias utilizadas como descritores na busca de informações nos PDIs analisados. Entre elas podemos destacar as seguintes: afro; afrodescendente; raça; racial; étnico; étnicas e étnico-racial. Em alguns dos documentos estas palavras não são citadas uma única vez. Noutros casos, o descritor ñnclusãoò aparece apenas ou quase que exclusivamente como referência a inclusão digital ou de pessoas com necessidades especiais.

Percebemos ainda que, em relação às IES comunitárias analisadas, as universidades públicas demonstram mais aptidão em incluir tais demandas em seus documentos.

O PDI da IES P2, seguido pelo PDI da IES P3, talvez sejam os que melhor demonstram às práticas adotadas em relação ao processo de reconhecimento e promoção de políticas e ações voltadas a obrigatoriedade da História e Cultura Afro-Brasileira e Africana, assim como da Educação das Relações Étnico-Raciais no ensino superior. Nele, conseguimos observar de forma mais objetiva a consecução do que consta nos documentos do Ministério da Educação /CNE.

De uma maneira geral, os documentos de algumas destas IES estão muito aquém do que poderia ser proposto, fato esse que pode ser considerado bastante grave uma vez que pouco ou nada está sendo dito sobre o trabalho desenvolvido a partir das políticas públicas de inclusão. Resta a dúvida se as ações em relação ao que preconizam os documentos legais existem, mas não são referenciadas, ou se nestas instituições existe de fato um déficit em relação ao que preconizam os documentos.

A falta de divulgação das experiências pedagógicas, as dúvidas e dificuldades dos professores em relação ao trabalho com a questão racial assim como a falta de articulação entre as IES, a educação básica e os movimentos sociais, são sintomas de um modelo de educação que encontra dificuldades em realizar de forma mais efetiva um diálogo que ultrapasse as barreiras disciplinares em favor de uma visão sistêmica da educação, das instituições de ensino e da sociedade na qual estas se inserem.

Não fica claro como o corpo docente é preparado para as ações necessárias à incorporação das práticas voltadas à educação das relações étnico-raciais. Poucas são as instituições que possuem grupos ou núcleos de estudo específicos sobre o tema, como é o caso da IES P3, que conta com uma Comissão Especial de Estudos sobre História e Cultura Afro-Brasileira e Indígena, ou a IES P2, que possui um Núcleo de Estudos Afro-Brasileiros, e uma Comissão de Implementação e Acompanhamento do Programa de Ações Afirmativas de Inclusão Racial e Social. Não encontramos referências nas IES pesquisadas à organização de centros de documentação, exposições, produção de materiais didáticos ou outras fontes ou atividades voltadas à temática da cultura afro-brasileira.

Ações de grupos de estudo e pesquisas formados para tais fins podem tornar-se locais de referência na formação e educação continuada de professores, inclusive para o ensino 
superior. Da mesma forma, a inclusão da Educação das Relações Étnico-Raciais, de conhecimentos de matriz africana e/ou que dizem respeito à população negra, nos conteúdos de disciplinas e em atividades curriculares dos cursos superiores, viria a agregar valor aos cursos oferecidos por estas IES, uma vez que possibilitaria o trabalho com outros tipos de sensibilidades e visões de mundo, elevando o grau de discernimento e compreensão da realidade brasileira por parte dos futuros profissionais, além, é claro, de atender aos quesitos legais sobre o tema.

\section{Referências}

ABRUC. Estatuto ABRUC. $1995 . \quad$ Disponível em: http://www.abruc.org.br/005/00502002.asp?ttCD_CHAVE=3550. Acesso em: 03/04/2019.

BRASIL. LEI № 10.639, DE 9 DE JANEIRO DE 2003. Disponível em: <http://www.planalto.gov.br/ccivil_03/leis/2003/110.639.htm>. Acesso em: 22/02/2019.

- Resolução CNE/CP no 1/2004. Disponível em: http://portal.mec.gov.br/cne/arquivos/pdf/003.pdf. Acesso em: 02/12/2019.

Parecer CNE/CP 3/2004. Disponível em: <http://portal.mec.gov.br/cne/arquivos/pdf/003.pdf>. Acesso em: 02/12/2019. CONSELHO NACIONAL DE EDUCAÇÃO. CONSELHO PLENO. RESOLUÇÃO № 1, DE 17 DE JUNHO DE 2004. Disponível em: <http://portal.mec.gov.br/cne/arquivos/pdf/res012004.pdf> Acesso em 30/10/2019.

LEI № 11.645, DE 10 MARÇO DE 2008. Disponível em: <http://www.planalto.gov.br/ccivil_03/_ato2007-2010/2008/lei/l11645.htm> Acesso em: 22/02/2019.

LEI № 12.288, DE 20 DE JULHO DE 2010. Disponível em: <http://www.planalto.gov.br/ccivil_03/_Ato2007-2010/2010/Lei/L12288.htm>. Acesso em: 20/02/2019.

LEI № 12.771, DE 28 DE DEZEMBRO DE 2012. Disponível em: <http://www.planalto.gov.br/ccivil_03/_Ato2011-2014/2012/Lei/L12771.htm>. Acesso em: 20/02/2019.

Formulário do Plano de Desenvolvimento Institucional ï PDI. 2015. Disponível em: <http://www2.mec.gov.br/sapiens/Form_PDI.htm>. Acesso em: 22/03/2019.

COMUNG; ACAFE. Contribuição do COMUNG1 e da ACAFE para a elaboração do Documento Referência do Fórum Nacional de Educação Superior. 2008. Disponível em: <http://portal.mec.gov.br/dmdocuments/comung_acafe.pdf > Acesso em: 24/02/2019.

DIMMOCK, Clive. La comparación de organizaciones educativas. In: BRAY, Mark; ADAMSON, Bob; MASON, Mark. Educación comparada: enfoques y métodos. Buenos Aires: Granica, 2010. 
FLICK. Uwe. Uma introdução à pesquisa qualitativa. Porto Alegre: Bookman, 2004.

IES C1. Plano de Desenvolvimento Institucional ï PDI. Disponível em: <http://.edu.br/public/media/4/files/pdi_livreto_web.pdf> Acesso em: 12/03/ 2019.

IES C2. Plano de Desenvolvimento Institucional ï PDI. Disponível em: <http://www.edu.br/htmlarea/midia/editais_e_publicacoes/39605112014150245.pdf> Acesso em: 3/03/ 2019.

IES C3. Plano de Desenvolvimento Institucional ï PDI. Porto Alegre: 2011.

IES P1. Plano de Desenvolvimento Institucional ï PDI. Disponível em: <http://www.br/ufrgs/arquivos/pdi-2010/view> Acesso em: 15/01/2019.

IES P2. Plano de Desenvolvimento Institucional ï PDI. Disponível em: <http://site.br/arquivos/uploaded/arquivos/be1eb2e0-4629-442e-b1af-79c251e3ac83.pdf > Acesso em: 18/01/2019.

IES P3. Plano de Desenvolvimento Institucional ï PDI. Disponível em: <http://porteiras.r.edu.br/portais/consuni/files/2010/06/Res.-71_2014-PDI.pdf> Acesso em:22/01/2019.

MIR, Luís. Guerra civil: estado e trauma. São Paulo: Geração Editorial, 2004.

MORAES, Roque; GALIAZZI, Maria do Carmo. Análise textual discursiva. ljuí: Ed. Unijuí, 2007.

Paula, Marilene de. Políticas de ação afirmativa para negros no governo Fernando Henrique Cardoso (1995-2002). Dissertação (mestrado) ï Centro de Pesquisa e Documentação de História Contemporânea do Brasil, Programa de Pós-Graduação em História, Política e Bens Culturais, 2010.

Picawy, Maria Maira. PDI - Plano de Desenvolvimento Institucional, PPI - Projeto Pedagógico Institucional e PPC - Projeto Pedagógico de Curso, entre o dito e o feito, uma análise da implementação em três IES/RS/Brasil. Tese. (Doutorado) ï Faculdade de Educação. Programa de Pós Graduação em Educação. PUCRS, 2008.

RIO GRANDE DO SUL. Secretaria de Educação do Estado do Rio Grande do Sul. Disponível em <www.educacao.rs.gov.br>. Acesso em: 08/01/2019.

SANTOS, João Paulo de Faria. Ações afirmativas e igualdade racial: a contribuição do direito na construção de um Brasil diverso. São Paulo: Loyola, 2005.

SEGENREICH, Stella Cecília Duarte. O PDI como referente para avaliação de instituições de educação superior: lições de uma experiência. Ensaio: aval. pol. públ. Educ., Rio de Janeiro, v. 13, n. 47, Jan. 2005.

VENANZI, Délvio; SANDANO, Wilson. Universidades comunitárias: as características na prestação de serviços públicos. Revista Temas em Educação. João Pessoa, v.23, n.2, p. 140-155, jul.-dez. 2014. 